\title{
The effect of preservatives and flavour additive on the production of oxygen-free radicals by isolated human neutrophils
}

\author{
E. Al-Shammari ${ }^{1}$, R. Bano ${ }^{1,}$,, S. Khan $^{1}$, I. Shankity ${ }^{2}$ \\ ${ }^{1}$ Department of Clinical Nutrition, College of Applied Medical Sciences, University of Hail, Hail, Ksa \\ ${ }^{2}$ Department of Clinical Laboratory Sciences, College of Applied Medical Sciences, University of Hail, Hail, Ksa \\ Email address: \\ rafiazafar78@gmail.com (R. Bano)
}

\section{To cite this article:}

E. Al-Shammari, R. Bano, S. Khan, I. Shankity. The Effect of Preservatives and Flavour Additive on the Production of Oxygen-Free Radicals by Isolated Human Neutrophils. International Journal of Nutrition and Food Sciences. Vol. 3, No. 3, 2014, pp. $210-215$. doi: $10.11648 /$ j.ijnfs.20140303.23

\begin{abstract}
Introduction: Researchers have recently described a relationship between food additives and immune system responses. A decline in immune response has also been observed in people who are in contact with food additives, such as preservatives and flavours found in different foods. Objectives: The objective of the present study was to investigate the in vitro effect of food additives, such as vanillin, Monosodium L- glutamate, Sodium Benzoate, and potassium nitrate, on the production of oxygen free radicals (OFRs) by isolated human nutrophils. Methods: The study was based on the isolation of neutrophils (polymorphonuclear leukocytes; PMNs) from normal blood to determine the effects of preservatives and flavouring additives on the production of Oxygen Free Radicals by stimulated PMNs. The study was carried out in the department of Clinical Nutrition, College of Applied Medical Sciences, University of Hail, Saudi Arabia. Results: After compleating the research it was found that most of the food preservatives and flavouring additives produced a significant inhibitory effect on the production of OFRs by isolated human PMNs. Higher concentrations of most of the food additives had significant effects on the chemiluminescence's response. However, moderate effects have been seen with most of the food additives at lower concentrations. Conclusion : Most of the food additives used in this study produced a significant effect on the oxidative respiratory burst and phagocytosis of isolated human PMNs. As there are few comprehensive studies in this field, we recommend that the responsible agencies conduct further investigations regarding the effects of these additives, as well as their complications.
\end{abstract}

Keywords: Preservative, Flavouring Agent, Food Additive, Neutrophils, Oxygen Free Radicals

\section{Introduction}

Nowadays, most people often eat convenient processed food in the supermarket, rather than preparing them at home. Many of them have at least one or two additives / preservatives. More than 3000 additives and preservatives can be found in such processed foods. For some food there are incredible numbers of additives can be found, such as cookies, chocolate, and gums.

When the food is to be stored for a long period, additives and preservatives are used to keep quality and flavor. The additives and preservatives prevents the excess water in the foods causing bacteria and fungal growth. ${ }^{[1]}$

Additives are defined by the United States Food and Drug Administration (FDA) as "any substance, the intended use of which results or may reasonably be expected to result, directly or indirectly, in its becoming a component or otherwise affecting the characteristics of any food." In other words, an additive is any substance that is added to food. Direct additives are those that are intentionally added to foods for a specific purpose. Indirect additives are those to which the food is exposed during processing, packaging, or storing. Preservatives are additives that inhibit the growth of bacteria, yeasts, and molds in foods. ${ }^{\text {[2] }}$

Artificial flavors and flavor enhancers, the largest class of additives, function to make food taste better, or to give them a specific taste. Examples are salt, sugar, and vanilla, which are used to complement the flavor of certain foods. Synthetic flavoring agents, such as benzaldehyde for cherry or almond flavor, may be used to simulate natural flavors. Flavor enhancers, such as monosodium glutamate (MSG) 
intensify the flavor of other compounds in a food. Nitrites are also a controversial additive. When used in combination with salt, nitrites serve as antimicrobials and add flavor and color to meats. However, nitrite salts can react with certain amines in food to produce nitrosamines, many of which are known carcinogens. Food manufacturers must show that nitrosamines will not form in harmful amounts, or will be prevented from forming, in their products. The flavoring enhancer MSG is another controversial food additive. MSG is made commercially from a natural fermentation process using starch and sugar. Despite anecdotal reports of MSG triggering headaches or exacerbating asthma, the Joint Expert Committee on Food Additives of the United Nations Food and Agriculture Organization, the World Health Organization, the European Community's Scientific Committee for Food, the American Medical Association, and the National Academy of Sciences have all affirmed the safety of MSG at normal consumption levels. ${ }^{[2,3]}$

In the United States, food additives and preservatives play an important role in ensuring that the food supply remains the safest and most abundant in the world. A major task of the FDA is to regulate the use and approval of thousands of approved food additives, and to evaluate their safety. Despite consumer concern about use of food additives and preservatives, there is very little scientific evidence that they are harmful at the levels at which they are used. ${ }^{[4]}$

It is confirmed by many studies and experiments (both human and animal) over the past few decades that a number of food additives regularly used by the food industry can have adverse effect on health. In other words, they can be toxic. As far back as 1960s, Dr. Ben Feingold's research provided first groundbreaking information on their toxicity to vulnerable individuals and children. ${ }^{[5]}$

Yet, the FDA thus far has approved nearly 3,000 food additives, resulting in the average American consuming, as far back as 1985 , nearly $15 \mathrm{~g}$ of food additives a year. That includes preservatives, taste/colour enhancers texture modifiers, processing and nutritional agents. ${ }^{[5]}$

There are also many pathological adverse effects of food additives, the long list including upper respiratory system symptoms, allergic skin reactions, gastrointestinal disorders, asthma, migraine, conjunctivitis, and others. While not all food additives are potentially harmful to human health, most people don't know which ones are, and which ones aren't. And very few know their individual sensitivities. With that in mind, best thing one can do is to minimize intake of food additives in general. This is easier said than done, not only because they are in such a widespread use. The limitation to what you can learn from the "ingredients" label comes from the current law that requires the label to list only what is added by the final producer. ${ }^{[5,6]}$

In other words, you don't see the additives used by those supplying the final producer with its raw materials. Still, reading the labels are certainly recommended, and you can't go wrong with "the fewer additives, the better" rule. ${ }^{[5,7]}$
European and other countries around the world have developed several lists of additives. The E system, developed by the European Economic Community, is a list of food additives that is updated on a regular basis, including additives that are considered GRAS, and allows foods to move from country to country within the common market. $^{[8]}$

Sodium benzoate (E211), also called benzoate of soda, is white crystalline or granular sodium salt of benzoic acid, with the formula $\mathrm{C} 6 \mathrm{H} 5 \mathrm{COONa}$ It is soluble in water and slightly soluble in alcohol. It is widely used in the production of canned soda; over $50 \%$ of benzoate goes into the soft drink industry. ${ }^{[9]}$

Potassium nitrite (E249) is known as a colour fixative, as well as an antimicrobial agent. Nitrites can react with amines in food or in the body to form nitrosamines, which are potent carcinogens (Jones, 1992). Nitrites are used in cooked meats and sausages as a preservative and to give cured meats their characteristic flavour and colour. ${ }^{[9]}$

Vanillin is a white, needle-like crystal with the odour of vanilla. It is used very extensively along with the thousands of other flavouring agents. It is commonly used in such products as cake, soft drinks, chocolate, candy, crackers, instant noodles, bread, tobacco, wine, toothpaste, and perfume. Its structure is 4-hydroxy-3methoxybenzaldehyde. ${ }^{[8]}$

Monosodium L-glutamate (E621; MSG) is a flavour enhancer usually used in protein-rich foods, oriental foods, and soups to enhance the perception of other tastes, particularly meat. ${ }^{[10]}$

\subsection{Free Radicals Produced by Neutrophils}

Two types of free radicals are produced by neutrophils: macrophages and endothelial and other cells. The first type is represented by reactive oxygen intermediates (ROI), and the second type includes reactive nitrogen intermediates.

ROS and free radicals have been associated with many degenerative diseases, and they have also been implicated in the development of cardiovascular diseases ${ }^{[11]}$, cancer ${ }^{[12]}$, diabetes, and cataracts ${ }^{[13]}$. Studies have demonstrated that PMNs can oxidize low density lipoproteins, which are implicated in most cardiovascular diseases. ${ }^{[14]}$

\subsection{Oxygen Free Radicals}

Free radicals are highly reactive chemical species that contain one or two unpaired electrons in their outer shells. They can donate or accept the electron, take an electron from another molecule, or combine with non-radical species. Free radicals derived from phagocytic cells are very toxic to a wide variety of tissues. Singlet oxygen, a reactive and highly oxidizing form of oxygen, can pair with any cell membrane and tissue that can release electrons, thus resulting in a chain reaction that can damage tissues, cells, and genes, and change biochemical compounds. These changes contribute to the primary causes of many diseases. $\left.{ }^{[15,16}\right]$ 


\subsection{Objectives of the Present Study}

The objectives of the present study are to investigate the in vitro effect of specific food additives (carmoisine, indigo carmine, allura red, sodium benzoate, vanillin, MSG, and potassium nitrite) on the production of oxygen free radicals on isolated human neutrophils (PMNs), and to formulate appropriate recommendations for the relevant agencies and the food industry, based on the observations of the study.

\section{Materials and Methods}

Polymorphonuclear isolation medium was obtained from Robbins Scientific Corporation (Sunnyvale,CA) Lysine buffer $\left(\mathrm{NH}_{4} \mathrm{Cl}-0.87 \%\right)$, PMA, luminol (5-Amino-2,3dihydro-1,4-phthalazine dione) and phosphate buffered saline (PBS) were obtained from Sigma Chemical Company (St. Louis, MO). Conical centrifuge tubes and plain vacutainer tubes were purchased from Medical Technical Trading EST (Riyadh, Saudi Arabia). Evacuated blood collection tubes $\left(10 \mathrm{ml}\right.$; $\left.\operatorname{EDTA}\left(\mathrm{K}_{3}\right)\right)$ were obtained from Terumo and Venoject Europe, N.V. Food additive (vanillin) was purchased from United Flavors \& Fragrances Co. Ltd. (Sahab, Jordan). Potassium nitrite was purchased from Riedel-de Haen (Seelze, Germany). Sodium benzoate was purchased from N.V. Druorharm Rading (Amsterdam, Holland), and MSG from Ajinomoto Co. (Tokyo, Japan). All chemicals used were of reagent grade and used without further purification.

Experimental work was carried out at the Department of Nutrition, College of Applied medical science, University of Ha'il, Saudi Arabia.

\subsection{Separation of Polymorphonuclear Neutrophils (PMNS)}

Isolation of PMNs was carried out as described previously (Shalabi and Al-Tuwaijri, 1996; Mustafa and AlTuwaijri, 1992 $)^{[17,18]}$. Briefly, fresh blood was collected by venipuncture from healthy donors in sterile containers containing 0.47 mole $/ \mathrm{L}$ of $\operatorname{EDTA}\left(\mathrm{K}_{3}\right)$. Ten millilitres of the blood were layered over $3.5 \mathrm{ml}$ of PMN in a $15 \mathrm{ml}$ centrifuge tube and centrifuged at $1800 \mathrm{rpm}$ for $30 \mathrm{~min}$ in a JOUAN - B4 centrifuge. The resulting neutrophil layer was extracted and washed with $10 \mathrm{ml}$ of PBS, $\mathrm{pH} 7.4$, and centrifuged at $1500 \mathrm{rpm}$ for $10 \mathrm{~min}$. Five millilitres of $0.87 \%$ $\mathrm{NH} 4 \mathrm{Cl}$ were added to the PMN pellets and left to stand in a water bath at $37^{\circ} \mathrm{C}$ for $10 \mathrm{~min}$ to lyse the erythrocytes. The cells were then washed three times with PBS, and after the last wash, the pellet was resuspended in $1 \mathrm{ml}$ of PBS. The PMNs were counted and adjusted to $5 \times 10^{5}$ cells $/ \mathrm{ml}$. Viability was determined by $0.2 \%$ trypan blue exclusion test, and only PMNs with viability above $80 \%$ were used in the experiments ${ }^{[18]}$.

\subsection{Preparation of Phorbol Myristate Acetate (PMA)}

PMA (Sigma chemical Co.) was used to enhance and stimulate the metabolic burst of phagocytic cells. It was dissolved in DMSO to give a stock solution of $2 \mathrm{mg} / \mathrm{ml}$. This stock solution was stored at $-20^{\circ} \mathrm{C}$ until it was used. Working solution was freshly prepared by diluting $50 \mu 1$ of stock solution with $10 \mathrm{ml}$ PBS.

\subsection{Preparation of Luminal}

Luminol (5-amino-2,3-dihydro-1,4-phthalazine) was used to enhance chemiluminescence (CL); $1.77 \mathrm{mg}$ of luminol was dissolved in $1 \mathrm{ml}$ of DMSO (10M) and stored at $-20^{\circ} \mathrm{C}$. Then, $100 \mu \mathrm{l}$ of this stock solution was further diluted with $10 \mathrm{ml}$ of PBS prior to use.

\subsection{Stimulation of PMNs}

The PMNs were stimulated by PMA, which is a nonphysiological stimulant. ${ }^{[18]}$

\subsection{Concentration of Food Additives Used to Prime PMNs}

The concentrations of food additives used here is in accordance with the amounts approved by different agencies, including the Saudi Arabian Standards Organization (SASO). ${ }^{[19]}$

\subsection{Measurement of Oxygen Free Radicals (Ofrs) by Chemiluminescence (Cl) Technique}

CL has been an important tool during the last few decades, especially in the assessment of bactericidal and phagocyte activity of various phagocyte cells. ${ }^{[17,18]}$ The technique uses luminol to increase the amount of measurable light during phagocytosis. CL was measured by using an AutoLumat Plus (Berthold, Bad Wilbad, Germany) with a controller set at a constant temperature of $37^{\circ} \mathrm{C}$. The luminometer was connected to an IBM-compatible computer, which recorded the light output, in $\mathrm{mV}$, continuously for $30 \mathrm{~min}$.

In brief, a $100 \mu 1$ PMN suspension was placed in $400 \mu 1$ PBS and $100 \mu 1$ food additive. Luminol $(200 \mu 1)$ and the stimulant PMN $(200 \mu 1)$ were then added. For control, $500 \mu 1$ of PBS was used. The cuvette contents were mixed gently. The light output was recorded in $\mathrm{mV}$ for $30 \mathrm{~min}$, and the maximum peak response was noted.

\subsection{PMN Viability Tests}

The percentage of viable PMNs was estimated by the trypan blue exclusion method, which was carried out by a microscopic count of cells not stained by $0.2 \%$ trypan blue; the quantity was expressed as percentage of unstained cells to total cell numbers. ${ }^{[17]}$

\section{Statistical Analysis}

Student's t-test was used to analyse the data for significant inter group comparisons. The values were consider significant if the $\mathrm{P}$ value was $<0.001$ or $<0.05$. Values are expressed as the mean \pm standard error of mean (SEM) of four observations. 


\section{Results}

In order to rule out any adverse cytotoxic effects of food additives and PMA, the viability of primed PMNs were tested at the lowest and highest concentrations of additives, as described previously (Metcalf et al., 1986). The results showed that different types of food additives did not alter the cell viability of the neutrophils. There was no blue staining of the nucleus. The percentage of viable cells as evaluated by trypan blue $(0.2 \% \mathrm{v} / \mathrm{w})$ was within normal limits after incubation with various food additives.

\subsection{Effect of Sodium Benzoate (E211) on OFR Production by PMNs}

Sodium benzoate (E211) was added to the PMNs at various concentrations $(5-0.375 \mathrm{mg} / \mathrm{ml})$. When stimulated by PMA, these primed PMNs showed significant inhibition of CL peak response compared with the control (Table 1). Inhibition was lowest at a concentration of $0.25 \mathrm{mg} / \mathrm{ml}$. The maximum peak response of the PMNs was observed at concentrations of $5-0.25 \mathrm{mg} / \mathrm{ml}$ (Table 1). Sodium benzoate concentrations of 0.125 and $0.05 \mathrm{mg} / \mathrm{ml}$ did not induce statistically significant changes in CL response compared with the control. The human neutrophils were primed with sodium benzoate for $30 \mathrm{~min}$ prior to PMA stimulation. The maximal increase in $\mathrm{CL}$ peak response $(\mathrm{mV})$ was measured at $17-25 \mathrm{~min}$ after stimulation, followed by a gradual decline in OFR release.

Table 1. Effect of various concentrations of sodium benzoate on chemiluminescence (CL) peak response and percentage of inhibition of isolated human PMNs stimulated with PMA

\begin{tabular}{cccc}
\hline $\begin{array}{c}\text { Sodium benzoate } \\
(\mathbf{m g} / \mathbf{m l})\end{array}$ & $\begin{array}{c}\text { CL max. peak } \\
\text { response }(\mathbf{m V})\end{array}$ & $\begin{array}{c}\text { P } \\
\text { value* }\end{array}$ & $\begin{array}{c}\text { CL inhibition } \\
(\mathbf{\%})\end{array}$ \\
\hline Control & $558.73 \pm 15.45$ & - & - \\
5.00 & $115.60 \pm 3.790$ & $<0.001$ & 79.31 \\
3.75 & $133.91 \pm 4.060$ & $<0.001$ & 76.03 \\
2.50 & $153.59 \pm 4.570$ & $<0.001$ & 72.51 \\
1.25 & $251.94 \pm 6.190$ & $<0.001$ & 54.91 \\
0.50 & $382.42 \pm 10.46$ & $<0.001$ & 31.55 \\
0.375 & $460.35 \pm 12.36$ & $<0.001$ & 17.61 \\
0.25 & $524.55 \pm 14.57$ & $<0.05$ & 6.120 \\
0.125 & $589.82 \pm 16.60$ & $\mathrm{NS}$ & -5.560 \\
0.05 & $606.21 \pm 16.91$ & $\mathrm{NS}$ & -8.500 \\
\hline
\end{tabular}

* Student's t test. NS = not significant.

Values are expressed as the mean \pm SEM of four observations.

PMNs count $=5 \times 105$ cell $/ \mathrm{ml}$. Luminol $=10-4 \mathrm{M}$. PMA $=2 \mu \mathrm{g} / \mathrm{ml} . \mathrm{CL} \%$

inhibition $=\mathrm{a}-\mathrm{b} / \mathrm{a} \times 100$, where (a) is the CL response of the control and (b)

is the CL response of the experiments.

\subsection{Effect of Monosodium L-Glutamate (MSG) (E621) on OFR Production by PMNs}

The addition of various concentrations of MSG to the PMNs prior to PMA stimulation significantly enhanced the CL peak response compared with the control (Table 2). The highest peak responses were observed at concentrations of $0.75, \quad 0.5,0.075$, and $0.05 \mathrm{mg} / \mathrm{ml}$, whereas other concentrations did not produce any significant effect on CL response. Human neutrophils primed with MSG for $30 \mathrm{~min}$ prior to PMA stimulation showed a maximum increase in CL peak response (mV) 11-14 min after stimulation, followed by a gradual decline in OFR release.

Table 2. Effect of various concentrations of monosodium glutamate (MSG) on chemiluminescence (CL) peak response and percentage of inhibition of isolated human PMNs stimulated with PMA

\begin{tabular}{cccc}
\hline $\begin{array}{c}\text { Monosodium } \\
\text { glutamate }(\mathbf{m g} / \mathbf{m l})\end{array}$ & $\begin{array}{c}\text { CL max. peak } \\
\text { response }(\mathbf{m V})\end{array}$ & $\begin{array}{c}\text { P } \\
\text { value* }\end{array}$ & $\begin{array}{c}\text { CL inhibition } \\
(\%)\end{array}$ \\
\hline Control & $466.31 \pm 17.49$ & - & - \\
1.00 & $487.79 \pm 15.44$ & NS & -4.60605 \\
0.75 & $498.99 \pm 15.43$ & $<0.05$ & -7.00826 \\
0.50 & $500.02 \pm 14.97$ & $<0.05$ & -7.22933 \\
0.25 & $492.79 \pm 14.17$ & NS & -5.67956 \\
0.10 & $468.45 \pm 13.76$ & NS & -0.45910 \\
0.075 & $532.26 \pm 17.55$ & $<0.05$ & -14.1439 \\
0.050 & $528.06 \pm 17.74$ & $<0.05$ & -13.2429 \\
0.025 & $508.51 \pm 17.74$ & NS & -9.04948 \\
0.010 & $497.71 \pm 18.13$ & NS & -6.73377 \\
\hline
\end{tabular}

* Student's t test. NS = not significant.

Values are expressed as the mean \pm SEM of four observations. $\mathrm{PMNs}$ count $=5 \times 10^{5} \mathrm{cell} / \mathrm{ml}$. Luminol $=10^{-4 \mathrm{M}}$. PMA $=2 \mu \mathrm{g} / \mathrm{ml} . \mathrm{CL} \%$ inhibition=a-b/a $\times 100$, where (a) is the CL response of the control and (b) is the CL response of the experiments.

\subsection{Effect of Vanillin on OFR Production by PMNs}

The addition of various concentrations of vanillin to the PMNs significantly inhibited the CL peak response after being stimulated by PMA compared with the control. The inhibition of $C L$ peak response $(p<0.001)$ was observed at concentrations of $0.01-0.0010 \mathrm{mg} / \mathrm{ml}$, as shown in Table 3 . While there were significant increases at concentrations of $0.00025-0.00010 \mathrm{mg} / \mathrm{ml}$ of vanillin, concentrations of 0.00075 and $0.0005 \mathrm{mg} / \mathrm{ml}$ did not induce statistically significant changes in CL response when compared with the control. Human neutrophils primed with vanillin for 30 min prior to PMA stimulation showed a maximum increase in CL peak response $(\mathrm{mV})$ 11-17 min after stimulation, followed by a gradual decline in OFR release. The percentage of inhibition was more significant at higher concentrations, as shown in table 3 .

Table 3. Effect of various concentrations of vanillin on chemiluminescence (CL) peak response and percentage of inhibition of isolated human PMNS stimulated with PMA

\begin{tabular}{cccc}
\hline $\begin{array}{c}\text { Vanillin } \\
(\mathbf{m g} / \mathbf{m l})\end{array}$ & $\begin{array}{c}\text { CL max. peak } \\
\text { response }(\mathbf{m V})\end{array}$ & $\begin{array}{c}\text { P } \\
\text { value* }\end{array}$ & $\begin{array}{c}\text { CL inhibition } \\
(\%)\end{array}$ \\
\hline Control & $936.080 \pm 28.91$ & - & - \\
0.01 & $250.970 \pm 8.150$ & $<0.001$ & 73.19 \\
0.0075 & $317.470 \pm 9.660$ & $<0.001$ & 66.09 \\
0.005 & $402.160 \pm 12.09$ & $<0.001$ & 57.04 \\
0.0250 & $593.200 \pm 15.83$ & $<0.001$ & 36.63 \\
0.001 & $787.450 \pm 20.22$ & $<0.001$ & 15.88 \\
0.00075 & $846.170 \pm 22.27$ & $\mathrm{NS}$ & 9.61 \\
0.0005 & $938.670 \pm 24.05$ & $\mathrm{NS}$ & -0.28 \\
0.00025 & $1083.65 \pm 27.62$ & $<0.001$ & -15.76 \\
0.0001 & $1212.65 \pm 30.12$ & $<0.001$ & -29.55 \\
\hline
\end{tabular}

* Student's t test. NS = not significant.

Values are expressed as the mean \pm SEM of four observations.

$\mathrm{PMNs}$ count $=5 \times 10^{5} \mathrm{cell} / \mathrm{ml}$. Luminol $=10^{-4 \mathrm{M}}$. PMA $=2 \mu \mathrm{g} / \mathrm{ml} . \mathrm{CL} \%$

inhibition=a-b/a $\times 100$, where (a) is the CL response of the control and (b) is the CL response of the experiments. 


\subsection{Effect of Potassium Nitrite (E249) on OFR Production by PMNs}

The effect of various concentrations of potassium nitrite on PMNs is shown in Table 4. The inhibition $(\mathrm{p}<0.05)$ of CL peak response was observed only with $0.01 \mathrm{mg} / \mathrm{ml}$ of potassium nitrite. However, a significant increase was observed at concentrations of 0.0005, 0.00025, and $0.00010 \mathrm{mg} / \mathrm{ml}$, as shown in Table 4. The addition of potassium nitrite at concentrations of 0.0075 $0.00075 \mathrm{mg} / \mathrm{ml}$ did not induce statistically significant changes in CL response when compared with the control. Human neutrophils primed with potassium nitrite for 30 min prior to PMA stimulation showed a maximum increase in CL peak response $(\mathrm{mV})$ 13-15 min after stimulation, followed by a gradual decline in OFR release.

Table 4. Effect of various concentrations of potassium nitrite (E249) on chemiluminescence (CL) peak response and percentage of inhibition of isolated human PMNs stimulated with PMA

\begin{tabular}{cccc}
\hline $\begin{array}{c}\text { Potassium nitrite } \\
(\mathbf{m g} / \mathbf{m l})\end{array}$ & $\begin{array}{c}\text { CL max. peak } \\
\text { response }(\mathbf{m V})\end{array}$ & $\begin{array}{c}\text { P } \\
\text { value* }\end{array}$ & $\begin{array}{c}\text { CL inhibition } \\
(\%)\end{array}$ \\
\hline Control & $304.18 \pm 10.41$ & - & - \\
0.01 & $274.59 \pm 9.390$ & $<0.05$ & 9.73 \\
0.0075 & $279.04 \pm 9.520$ & NS & 8.26 \\
0.005 & $296.64 \pm 10.20$ & NS & 2.48 \\
0.0025 & $315.91 \pm 10.85$ & NS & -3.86 \\
0.001 & $314.30 \pm 10.64$ & NS & -3.33 \\
0.00075 & $312.20 \pm 10.40$ & NS & -2.64 \\
0.0005 & $347.81 \pm 11.65$ & $<0.05$ & -14.35 \\
0.00025 & $342.76 \pm 11.32$ & $<0.05$ & -12.68 \\
0.0001 & $353.82 \pm 11.59$ & $<0.05$ & -16.32 \\
\hline
\end{tabular}

* Student's t test.NS = not significant.

Values are expressed as the mean \pm SEM of four observations. $\mathrm{PMNs}$ count $=5 \times 10^{5} \mathrm{cell} / \mathrm{ml}$. Luminol $=10^{-4 \mathrm{M}}$. PMA $=2 \mu \mathrm{g} / \mathrm{ml} . \mathrm{CL} \%$ inhibition $=\mathrm{a}-\mathrm{b} / \mathrm{a} \times 100$, where (a) is the CL response of the control and (b) is the CL response of the experiments.

\section{Discussion}

The present study demonstrates that certain food preservatives and flavouring substances (sodium benzoate, vanillin, MSG, and potassium nitrite) significantly inhibit the luminol-dependent $\mathrm{CL}$ response of isolated human PMNs stimulated by PMA, mostly at higher concentrations. Arouma and Halliwell ${ }^{[20]}$ reported that any defect in neutrophil activity might predispose the individual to increased susceptibility to infection. This finding indirectly reflects decreased neutrophil activity, and hence, the production of OFR.

It is a well known fact that humans are significantly exposed to food additives as a constituent of many foods and drinks consumed every day. There is lot of evidence that several kinds of food additives can initiate adverse reactions in the biological systems of humans. ${ }^{[8,21]}$

While humans are widely exposed to food flavouring agents, the immunotoxicity of these substances has not been extensively studied. However, many studies have been conducted on the immunomodulatory effects of chemicals found in nature. ${ }^{[22,23]}$
Vanillin is used extensively as a food-grade flavouring agent. It is the most widely used flavour in foods, ranging from cake to soft drinks and baby cereals. It was observed here that various concentrations of vanillin cause significant inhibition of CL peak response. The reason vanillin is more effective in inhibiting CL peak response could be due to its antioxidant nature. The antioxidant potential of vanillin was discovered by Aruoma et al., in 1991.20 MSG has been shown to cause numbness of the neck, headache, facial pressure, and chest pain. However, little work has been conducted on the effect of MSG on OFR production by PMNs and its effect on the immune system. ${ }^{[24]}$

Benzoic acid, benzoate, nitrites, and nitrates are known to cause urticaria on the lips and oral mucosa. Sodium benzoate and potassium nitrate are used extensively in food preservation ${ }^{[25]}$. In the present study, sodium benzoate was shown to cause significant inhibition in the CL peak response at concentrations of $5-2.5 \mathrm{mg} / \mathrm{ml}$. In contrast, potassium nitrite caused significant inhibition at only $0.01 \mathrm{mg} / \mathrm{ml}$, while the other concentrations tested either had no effect on CL peak response or caused a significant increase in CL peak response.

It can be inferred from the above findings that most of the additives used have an inhibitory effect on CL peak response/OFR production. Thus, it can be speculated that they can affect the immune system.

\section{Conclusion and Recommendations}

In Saudi Arabia, a wide variety of food additives are used commonly in all food products to offset flavour loss due to storage or processing and to increase the shelf life. Flavouring agents are used commonly in such products as cakes, soft drinks, chocolate, candy, crackers, instant noodles, bread, tobacco, wine, toothpaste, and perfume.

In the Gulf area, the standards that are followed are based on the decision of the Board of Directors in accordance with the decision of the Higher Council of the Gulf Cooperation Council (GCC) states, held in Bahrain on 23-01-1403. In Saudi Arabia, only some of the approved additives are used in food products and preservatives.

There is not always adequate scientific proof of whether or not a particular additive is safe; little or no data are available regarding the health risks or combined effects of these additive cocktails. ${ }^{[8]}$ There is lack of significant literature regarding this very important aspect from all parts of the world. Thus, we recommend that the responsible agencies conduct further investigations regarding the effects of these additives, as well as their complications. High concentrations of food additives are usually used in sweets, desserts, cereal bars, drinks, and almost all frozen manufactured foods. They are used to mask the poor quality of the ingredients in these foods. When people consume foods containing these additives in large amounts, they can experience toxic effects. In general, children's food should not contain additives, either natural or synthetic, because they provide a false expectation of food taste. 
Education programs should be designed, especially at the school level, to make the public aware of the effect of food additives on the immune system. People should be advised and encouraged to consume fresh fruits and vegetables, as they enhance immunity. The public should be encouraged to avoid the use of food additives as much as possible, especially the following: potassium nitrite, sodium benzoate, MSG, and vanillin, as these additives have an adverse effect on the immune system. Further ex vivo studies should be carried out on the effect of food additives on polymorphonuclear leukocytes.

\section{Summary Box}

\subsection{What's Already Done}

Some researchers have shown in their studies the effect of food additives on different areas of human health like allergies, hyperactivity in children and decrease in human immune response.

\subsection{What's New}

The present study proves the effect of some common food additives on the production of oxygen free radicals by isolated human neutrophils. This study points out the very important yet rarely explored topic, especially in the country like Saudi Arabia, where the use of foods having additives is very common. People either don't, know or just ignore the dangerous effect of these additives on the health of general population, especially children.

\section{References}

[1] How do food additives such as artificial flavors, preservatives, and others affect your physical well being, available at www.wholevegan.com/food_additives.html

[2] Branen, A. Larry (2002). Food Additives, 2nd edition. New York: Marcel Dekker.

[3] Clydesdale, Fergus M. (1997). Food Additives: Toxicology, Regulation, and Properties. Boca Raton, FL: CRC Press.

[4] Potter, Norman N., and Hotchkiss, Joseph H. (1995) Food Science, 5th edition. New York: Chapman \& Hall.

[5] Health knot.com, food additives and health, available at www.healthknot.com/food_additives.html

[6] Dalton, Louisa (11 2002). "Food Preservatives". Chemical and Engineering News 80 (45): 40. Retrieved 9 February 2012.

[7] "Using Preservatives". Food Additive AND Ingredients Association Retrieved 9 February 2012.

[8] Branen AL, Davidson M, Salminen S et al (2001). Food additives. Marcel Dekker London, 2nd Edition, pp. 1-8.

[9] Jones JM (1992). Food Safety. Eagan press, USA, 1st Edition, pp 203-299.

[10] Hriscu M, Saulea G, Vidrascu N et al (1997). Effects of monosodium glutamate on blood neutrophils phagocytic activity and phagocytic response in mice. Rom.J.Physiol., 34:95-101.

[11] Kumar V, Ganguly NK, Anand IS et al (1991). Release of oxygen free radicals by macrophages and neutrophils in patients with rheumatic fever. European Heart Journal, $12: 163-165$.

[12] Witz G (1991). Active oxygen species as factors in multistage carcinogenesis. Proceedings of the Society of Experimental Biology and Medicine, 198: 675-682.

[13] Opara EC (2002). Oxidative stress, micronutrients, diabetes mellitus and its complications. J. R. Soc. Health, 122: 28 34.

[14] Wieland E, Brandes A, and Oellerich M et al (1993). Oxidative modification of low density lipoproteins by human polymorphonuclear leukocytes. Eur.J.Clin.Chem.Clin. Biochem., 31: 725-731.

[15] Lauren S (1999). How the Immune System Works. Blackwell Science, Inc, United Kingdom, 8th Edition, pp 524.

[16] Aruoma OI and Halliwell B (1991). Free radicals and food additives. Taylor \& Francis, London, New York, Philadelphia, pp. 1-192

[17] Shalabi EA and Al-Tuwaijri AS (1996). The thermal potentiation of acetaminophen-inhibited PMN oxidative metabolism in vitro. Biopharmaceutics and drug disposition, 17: 501-509

[18] Mustafa AA and Al-Tuwaijiri AS (1992). Stimulated Chemilumienescence of isolated human polymorphonuclear leukocytes: in vitro inhibition; Melittin. journal of Natural Toxins, 1:65-76.

[19] Saudi Arabian Standards Organization (2011). Flavours permitted for use in foodstuffs.

[20] Aruoma OI and Halliwell B (1991). Free radicals and food additives. Taylor \& Francis, London, New York, Philadelphia, pp. 1-192

[21] Gaworski CL, Vollmuth TA, Dozier MM, Heck JD, Dunn LT, Ratajczak HV and Thomas PT (1994). An Immunotoxicity Assessment of food flavouring ingredients. Food Chem Toxic, 32:409-415.

[22] Murry MJ and Tomas PT (1992). Toxic consequences of chemical interactions with the immune system. In principles and practices of immunotoxicology. Blackwell Scientific, Oxford. pp. 65-85.

[23] Thomas P, Busse W, et al (1990). Immunologic effects of pesticides. In effects of Pesticides on Human Health. Advances in modern environmental Toxicology. Princeton Scientific, Princeton, NJ. pp. 261-296.

[24] Hriscu M, Saulea G, Vidrascu N and Baciu I (1997). Effects of monosodium glutamate on blood neutrophils phagocytic activity and phagocytic response in mice. Rom.J. Physiol., 34:95-101.

[25] Pierson MD and Smoot LA (1982). Nitrite Alternatives, and the control of Clostridium Botulinum in Cured meats. Crit. Rev. Food Sci. Nutr.,17: 141-187. 